\title{
TEMAS MAIS PESQUISADOS EM EDUCAÇÃO AMBIENTAL NA REVISTA BRASILEIRA DE EDUCAÇÃO AMBIENTAL
}

Angela Maria Kreuz ${ }^{1}$

Resumo: Este artigo, apresenta a contribuição da RevBEA, na divulgação de pesquisas sobre EA, identificando os temas pesquisados pelos autores, do ano de 2010 até 2016. O método da pesquisa é o Materialismo Histórico na Dialética Marxista. A pesquisa se caracteriza como metodologia do estado da arte, ou do conhecimento. As principais fases da investigação são: $1^{\circ}$ ) coleta de dados; $2^{\circ}$ ) sistematização dos dados; e $3^{\circ}$ ) análise dos dados. As 253 publicações on-line, em sete anos, envolveu 689 autores, que produziram pesquisas com diferentes objetivos, e temas. A abrangência da Revista transita pelas diferentes áreas de formação dos autores. Os temas que se destacam nas pesquisas, com maior produção, são: resíduos; EA nas escolas/colégios; ecologia e sustentabilidade.

Palavras-chave: Educação Ambiental; Revista; Tema; Revista Brasileira de Educação Ambiental

${ }^{1}$ Universidade Estadual do Oeste do Paraná. E-mail: angelamariakreuz2010@hotmail.com

Revbea, São Paulo, V. 13, № 3: 316-333, 2018. 


\section{Introdução}

As questões socioambientais fazem parte do cotidiano e trazem preocupações vinculadas desde a exploração irracional de recursos naturais que influencia no esgotamento de recursos não renováveis - até o crescimento das desigualdades socioeconômicas. Dessa maneira, torna-se perceptível a necessidade de maior responsabilidade em relação às ações humanas, haja vista que a Educação Ambiental (EA), por si só, em seu modo Formal ou NãoFormal, não é capaz de solucionar tais questões. Apesar disso, a EA cumpre papel importante na construção de valores ambientais menos impactantes ao meio ambiente, seja na formação inicial, ou em futuras ações relacionadas à conservação e preservação do meio ambiente.

Assim sendo, a presente pesquisa analisou o que se estuda sobre a EA na perspectiva das produções da RevBEA (Revista Brasileira de Educação Ambiental), por meio de um levantamento quantitativo de análise qualitativa dos temas das publicações na revista.

As pesquisas que possuem o perfil de caracterização da produção de caráter bibliográfico também são denominadas pesquisas do estado da arte ou estado do conhecimento e possuem como característica o mapeamento de diferentes produções. Esse meio de pesquisa permite o conhecimento da totalidade do que é estudado, o que é pesquisado e os resultados que uma determinada área do conhecimento apresenta. Como apontado por Ferreira (2002), o desafio de tal metodologia de pesquiOsa ocorre pelo desejo de conhecer o que já foi construído, além disso, visa divulgar para a sociedade e nortear novos processos de pesquisa.

Desse modo, o método utilizado para a análise na pesquisa é o materialismo histórico dialético na perspectiva da psicologia histórico-cultural pois, como aponta Zanella (2012), a Educação Ambiental por meio do método do materialismo histórico possibilita a superação de análises idealistas ou mecanicistas. Já, através da ótica trabalhadora, Marx apresenta uma perspectiva teórico-metodológica e de práxis, mostra a contradição da sociedade capitalista e como o sujeito histórico é transformador da sociedade.

Em relação à EA, o materialismo histórico "[...] se coloca a partir da totalidade de relações entre a base material da sociedade (infraestrutura) e a superestrutura (Estado, políticas, instituições, ideologias, ciências)" (ZANELLA, 2012, p. 35). Sendo assim, o homem faz a história a partir das leis do capital, ou seja, de condições determinadas.

\section{RevBEA: uma revista científica brasileira de Educação Ambiental}

A RevBEA, criada em 2004, manteve publicações impressas até 2010 e a partir desse ano passou a ter suas publicações on-line. Totaliza 24 revistas publicadas até 2016 , dentre elas, seis impressas e 18 on-line. Os volumes se apresentam em formato acadêmico e não acadêmico e aliam-se a inúmeras 
publicações nacionais e internacionais. Publicada em um período trimestral (março, junho, setembro e dezembro) as submissões on-line mantêm acesso livre. A revista é direcionada essencialmente à $E A$ e, preferencialmente, às atividades de pesquisa ou de vivências relacionadas ao tema, mas também aceita ensaios teóricos. É a única revista científica brasileira específica de EA. Para a submissão de artigos e relatos de experiência há um custo no valor de $R \$ 30,00$ por autor, referente ao expediente dos editais, às tarifas postais e a outros serviços de editoração e revisão (RevBEA, 2016).

A revista RevBEA tem uma proposta que visa o acolhimento dos textos produzidos no campo da Educação Ambiental, independentemente da sua natureza, postura que se justifica em função do vasto e heterogêneo perfil dos protagonistas que atuam nessa área no Brasil. Sua intenção não é disputar espaços com revistas acadêmicas. Ao revés, soma-se às inúmeras publicações internacionais e nacionais que vêm oferecendo possibilidade de visibilidade para vivências, experiências, ensaios ou reflexões teóricas sobre a EA (RevBEA, 2016, p. 01).

A qualificação por área do conhecimento, em 2016, apresenta-se da seguinte forma: qualis B2: Ciências Ambientais e Interdisciplinar; qualis B3: Ensino, Geografia e História; qualis B4: Administração, Ciências Contábeis, Turismo, Engenharias, Letras e Linguística; qualis B5: Ciências Agrárias, Educação Física, Engenharias, Geociências, Materiais, Medicina Veterinária, Psicologia e Serviço Social; qualis C: Biodiversidade, Ciências Biológicas e Saúde Coletiva.

A Tabela 1 (próxima página) apresenta as publicações do ano de 2010 a 2016 observadas com base nas publicações disponíveis do link: http://www.sbecotur.org.br/revbea/index.php/revbea.

Nos anos de 2005 e 2006 não houve nenhuma publicação da RevBEA. Tal fator ocorreu, conforme informou Rafael' ${ }^{21}$, editor da Revista ${ }^{31}$, por ainda estar em fase de consolidação e por seu formato e periodicidade não estarem definidos. Ele esclarece que:

Após os primeiros números, houve muitos debates pela Rede Brasileira de Educação Ambiental, e optou-se por retomar a Revista, e manter uma periodicidade somente a partir de 2007, não parando mais e aumentando o número de edições por ano gradativamente, o que de fato ocorreu (Rafael, 2017).

I Pseudônimo utilizado para preservar a identidade do entrevistado.

" Entrevista concedida via e-mail. 
Tabela 1: Produções da RevBEA de 2010 a 2016

\begin{tabular}{|c|c|c|c|c|c|}
\hline Ano & $\begin{array}{l}\text { Volume } \\
\text { Número }\end{array}$ & Publicações & Artigos & $\begin{array}{c}\text { Relatos de } \\
\text { Experiência }\end{array}$ & Autores \\
\hline 2010 & vol. 5 & 13 & 13 & 0 & 25 \\
\hline 2011 & vol. 6 & 10 & 10 & 0 & 20 \\
\hline \multirow[t]{3}{*}{2012} & vol. 7 n. 1 & 10 & 10 & 0 & 28 \\
\hline & vol. 7 n. 2 & 10 & 10 & 0 & 19 \\
\hline & vol. 7 n. 3 & AFBEA & AFBEA & AFBEA & AFBEA \\
\hline \multirow{2}{*}{2013} & vol. 8 n. 1 & 12 & 12 & 0 & 36 \\
\hline & vol.8 n. 2 & 12 & 11 & 1 & 40 \\
\hline \multirow{2}{*}{2014} & vol. 9 n. 1 & 13 & $10^{*}$ & 3 & 43 \\
\hline & vol. 9 n. 2 & 19 & 11 & 8 & 46 \\
\hline \multirow[t]{4}{*}{2015} & vol. 10 n. 1 & 20 & $17^{*}$ & 3 & 53 \\
\hline & vol. 10 n. 2 & 20 & $16^{*}$ & 4 & 56 \\
\hline & vol. 10 n. 3 & 16 & 12 & 4 & 47 \\
\hline & vol. 10 n. 4 & 9 & 4 & $5^{\star}$ & 31 \\
\hline \multirow[t]{5}{*}{2016} & vol. 11 n. 1 & 25 & $19^{*}$ & $6^{*}$ & 65 \\
\hline & vol. 11 n. 2 & 25 & 19 & 6 & 59 \\
\hline & vol. 11 n. 3 & A CBAAGT & A CBAAGT & A CBAAGT & A CBAAGT \\
\hline & vol. 11 n. 4 & 25 & 19 & 6 & 78 \\
\hline & vol. 11 n. 5 & 14 & 8 & 6 & 43 \\
\hline T. 0. & 18 revistas & 253 & 201 & 52 & 689 \\
\hline
\end{tabular}

Fonte: RevBEA, 2016./Org.: KREUZ, 2016.

Notas: T.O.: Total On-line; AFBEA: Anais da Federação Brasileira de Educação Ambiental; A CBAAGT: Anais do V Congresso Brasileiro de Educação Ambiental Aplicada e Gestão Territorial; * : publicações em inglês

Os dois volumes do ano de 2004 e os de 2007,2008 e 2009, tiveram suas edições impressas, totalizando cinco revistas publicadas.

Entre 2010 e 2016, anos em que a publicação foi exclusivamente on-line, foram publicadas 18 revistas com 201 artigos e 52 relatos de experiência totalizando, nesse período, 253 publicações e 689 autores envolvidos, tendo, ainda, ao todo, seis publicações em língua estrangeira: inglês.

Como a intenção desta pesquisa é realizar um recorte quantitativo, far-seá análise do número de publicações on-line; desse modo, as publicações impressas não serão analisas. Destarte, a análise dar-se-á pelos seis anos de volumes, com disponibilidade on-line.

Por meio da análise gráfica das produções da RevBEA é possível identificar que os anos de maior produção de publicações foram 2015 e 2016, devido ao início da trimestralização das publicações - sendo que, anteriormente, o número de edições anuais variava de uma a duas (Gráfico 1). Outro fator a se analisar refere-se ao número de publicações, ou seja, artigos e relatos de experiência bem como o número de autores aumentaram. 
Gráfico 1: Produções da RevBEA de 2010 a 2016

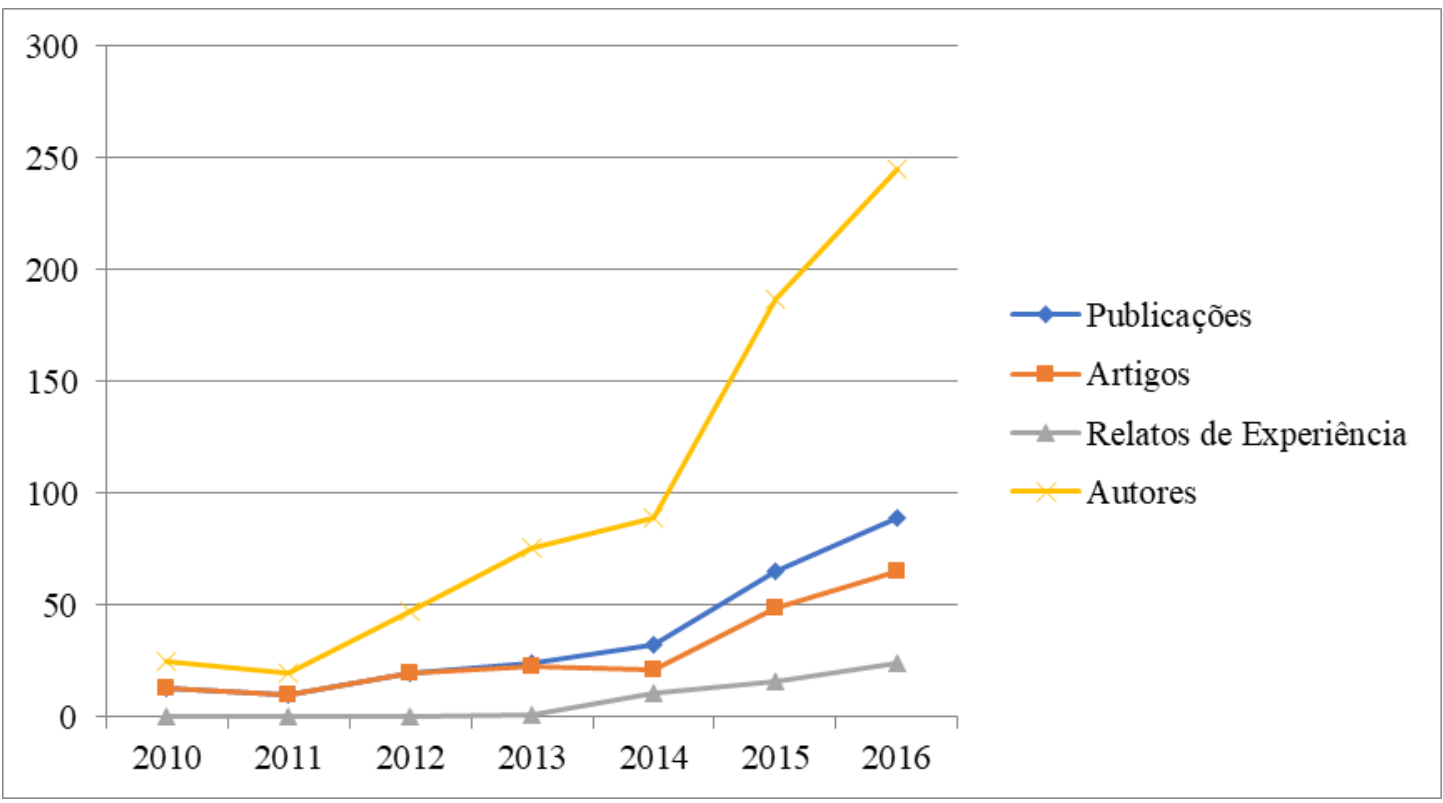

Fonte: RevBEA, 2016./Org.: KREUZ, 2016.

\section{Publicações com disponibilidade on-line na RevBEA}

O objetivo da pesquisa aqui relatada, foi analisar quais temáticas os autores das publicações da RevBEA, mais pesquisaram. Com isso, identificouse quantitativamente e qualitativamente as produções sobre o que foi divulgado para assim, compreender as abordagens, preocupações e problemáticas encontradas pelos autores da RevBEA.

Para o mapeamento dos principais temas pesquisados nas publicações da RevBEA, analisou-se o título dos artigos e relatos de experiência. Os dados apresentados estão por ordem decrescente da quantidade de pesquisas em determinado tema e, em seguida, por ordem alfabética. Existe uma grande heterogeneidade nas pesquisas analisadas.

A Tabela 2 apresenta as principais temáticas trabalhadas em EA analisadas por meio dos títulos das produções da RevBEA. Das 253 publicações da Revista, foram definidos 150 temas. O destaque é pela quantidade de publicações os temas Resíduos e Escola/Colégio, com 6,7\% e 5,1\% respectivamente. Outro, com maior número de publicações foram: Ecologia com 3,2\%; Sustentabilidade e Ensino Fundamental com 2,7\%; Lixo e Percepção Ambiental com 1,9\%; Conscientização Ambiental, EA Critica, Pesca, Recursos Hídricos e Trilha Ecológica com 1,5\%; e Educomunicação, Ensino de Geografia, Intenção e Ação, Jogos Didáticos e Reciclagem com 1,1\% publicações da Revista. 
Tabela 2: Temáticas que mais aparecem nas produções da RevBEA.

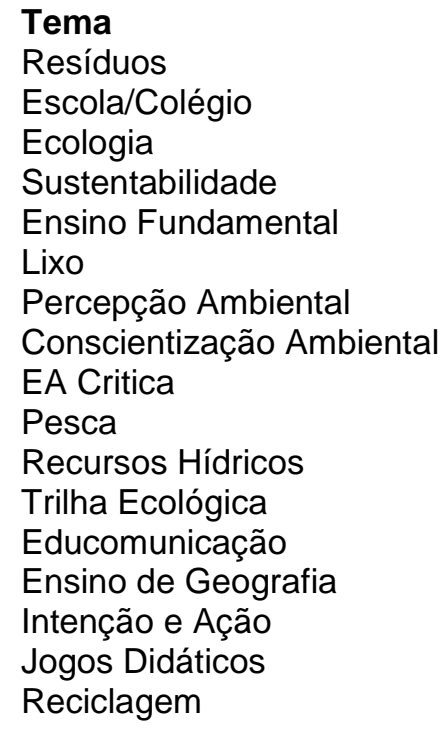

Total de Publicações: 96

$\begin{array}{lc}\text { Número } & \text { Porcentagem } \\ 16 & 6,71 \% \\ 13 & 5,13 \% \\ 8 & 3,16 \% \\ 7 & 2,76 \% \\ 7 & 2,76 \% \\ 5 & 1,97 \% \\ 5 & 1,97 \% \\ 4 & 1,58 \% \\ 4 & 1,58 \% \\ 4 & 1,58 \% \\ 4 & 1,58 \% \\ 4 & 1,58 \% \\ 3 & 1,18 \% \\ 3 & 1,18 \% \\ 3 & 1,18 \% \\ 3 & 1,18 \% \\ 3 & 1,18 \%\end{array}$

Fonte: RevBEA, 2016. Org.: KREUZ, 2016.

O Quadro 1 apresenta as temáticas que possuem duas publicações cada, totalizando 23 temas e 48 publicações. Ao todo, essas temáticas representam $18,1 \%$ das publicações da RevBEA.

Quadro 1: Temáticas que aparecem duas vezes nas produções da RevBEA.

Agenda 21
Biodiversidade
Coleta Solidária
Concepção de Meio Ambiente
Desenvolvimento Sustentável
Disciplina de EA
Ensino Médio
Ensino Público

Agenda 21

Biodiversidade

Coleta Solidária

Ensino Público

\section{Tema}

Etnobotânica
Formação de Professores
Geotecnologias
Gestão Socioambiental
Horta Escolar
Oficinas Educativas
Paisagem
PIBID

Total de Publicações: 48
Práticas Lúdicas

Práticas Pedagógicas

Probio-Educação

Saneamento

Saúde

Sensibilização Ambiental

Surdos

Unidades de Conservação

Fonte: RevBEA, 2016. Elaboração.: KREUZ, 2016.

O Quadro 2 apresenta as 109 temáticas que aparecem apenas em uma publicação da RevBEA. Ao todo, essas temáticas representam $43,50 \%$ das publicações da revista. 
Quadro 2: Temáticas que aparecem uma vez nas produções da RevBEA

Temas

Ações de EA

Ações Socioambientais

Administração Contábil

Agroecologia

Águas do Capibaribe

Área de Proteção Ambiental Costa dos Corais

Áreas Verdes Urbanas

Assentamento Rural

Atividades

Avanços na EA Brasileira

Bioética

Bitucas de Cigarro

Cachorro-Vinagre e EA

Carste de Minas Gerais

Carta da Terra

Catadores de Lixo

Centro de Visitação de EA

Chuva Ácida

Cisternas

Coleta Seletiva

Complexidade

Concepções e Saberes Pedagógicos

Conservação Ambiental

Conteúdos Curriculares do Ensino Superior

Cultivares de Mamoeira

Currículo Verde

Desafio Jogando Verde

Desastres Naturais

Dialética e Interdisciplinaridade

Dimensão Subjetiva na EA

Discurso e Prática

Ecocidadania

Ecoturismo

EA ao Ar Livre

EA Brasileira

EA Conservadora

EA Critica

EA Dialógico Problematizadora

EA Formal

EA Não-Formal

Educação do Campo

Educação de Jovens e Adultos

Educação Estética Ambiental

Educação Infantil

Empreendedorismo

Ensino

Ensino de Ciências

Ensino Profissionalizante

Ensino de Química

Escola Rural

Espaços Interativos

Esportes na Natureza

Etnofarmacologia

Flora

Formação do Pedagogo
Formação Continuada

Formulação de um Conceito Operacional

Fronteira Oeste do Rio Grande do Sul

Geociências

Gestão Ambiental

Gestão Integrada

Globalização da Natureza

Imaginário

Intencionalidade Científica

Interação Sala de Aula/Comunidade

Interdisciplinaridade

Interpretação Ambiental

Jardim Botânico de Recife (JBR)

Lagoa das Capivaras, Garopaba (SC)

Licenciatura em Biologia

Literatura

Lixão

Mamíferos do Cerrado

Materiais Recicláveis

Material Didático

Método VERAH

Método Vivências

Mudança Climática

Museu de Ciência

Música

Organização Forçada

Parque Ecológico João "Domingos Coelho" (SP)

Parque Estadual do Morro do Diabo (SP)

Parques

Periódicos Brasileiros de Ensino de Física

Plano de Ação

Postais Brasileiros

Políticas Públicas

Prefeituras Municipais do Sudoeste do Paraná

Progr.de Assessoria Técnica, Social e Ambiental (ATES)

Programa Nacional de Escolas Sustentáveis (PNES)

Projeto Clube Tetéia

Projetos de EA

Rede PEA-Unesco

Reforma Agrária

Representação Social de Meio Ambiente e EA

Rio-92

Rompimento da Estabilidade Ambiental

Serviços Ecossistêmicos Culturais

Sistemas de Dessanilização

Sistema Único de Saúde (SUS)

Sociologia

Sujeito da Modernidade

Sustentabilidade

Técnico em Meio Ambiente

Tecnologias

Tecnologia de Informação Verde

Temáticas Ambientais

Transgênicos

Total: 109 
Além das informações acima descritas e analisadas, é fundamental compreender as problemáticas encontradas nos principais temas pesquisados na Revista.

\section{Os sete temas mais pesquisados na RevBEA}

Um fator fundamental, que deve ser o principal objetivo das divulgações ocorridas no campo da EA, é a finalidade dos autores das publicações desenvolverem seu papel de sujeitos políticos na sociedade. O campo editorial, sendo ele científico ou não, expõe e divulga à sociedade as preocupações, pesquisas e experiências em EA e, portanto, deve ser consolidado com a ação e efetivação coletiva. Nesse sentido, aponta Loureiro que "[...] pautada em permanentes reflexões teóricas que qualifiquem a prática, sendo por esta revista (práxis), caracterizando atividade política intensa", (2006, p. ,106). Esse fator visa fortalecer a troca de experiência, diálogos e debates no campo científico.

O autor também aponta que os indivíduos não são sujeitos apenas ecológicos e pedagógicos, mas também políticos. Sendo assim, é por meio da prática social que fazem história, produzem e reproduzem conhecimento por meio da problematização, fato que, consequentemente, provoca a transformação dos conhecimentos, valores e atitudes (LOUREIRO, 2006). Para isso ocorrer é necessário agir politicamente, fazendo parte da identificação de problemas.

Sendo assim, com o intuito de compreender o papel político dos autores das produções da Revista foi desenvolvida da análise dos principais temas pesquisados pelos autores da Revista.

Das 253 publicações na RevBEA, sete (7) temas foram destaque, sendo eles: resíduos; EA na escola/colégio; ecologia; sustentabilidade; EA no Ensino Fundamental; lixo e percepção ambiental, totalizando 61 publicações. Para compreender a importância desses temas e como as pesquisas foram desenvolvidas, segue o Quadro $3 \mathrm{com}$ pesquisas da RevBEA que trabalharam com o tema de resíduos, abrangendo diferentes abordagens e objetivos e resultados. Os resíduos sólidos se destacam entre as problemáticas, demonstrando ser uma preocupação de diversos pesquisadores. Dentre os autores mais utilizados pelos pesquisadores, estão Lucie Sauvé e Edgar Morin. 
Quadro 3: Pesquisas sobre resíduos.

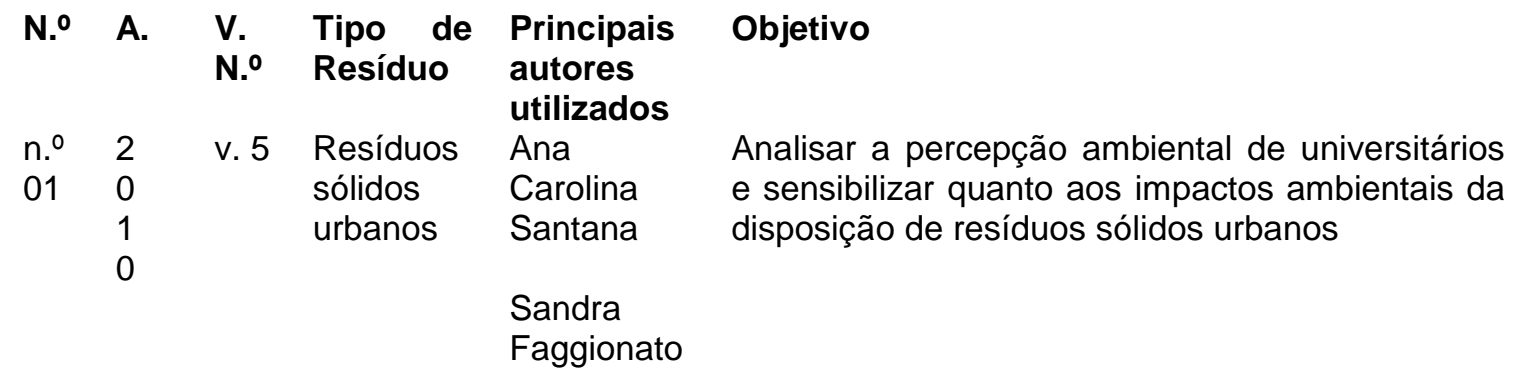

$\begin{array}{lllll}\text { n.․․ } & 2 & \text { v. } & \text { Resíduos } & \text { Edgar } \\ 02 & 0 & 7 & \text { sólidos } & \text { Morin } \\ & 1 & \text { n.․ } & \text { em } & \\ & 2 & 1 & \begin{array}{l}\text { instituição } \\ \text { de ensino } \\ \text { superior }\end{array} & \text { Genebaldo } \\ & & & \text { Freire Dias }\end{array}$

Construir políticas de gestão dos resíduos numa universidade.

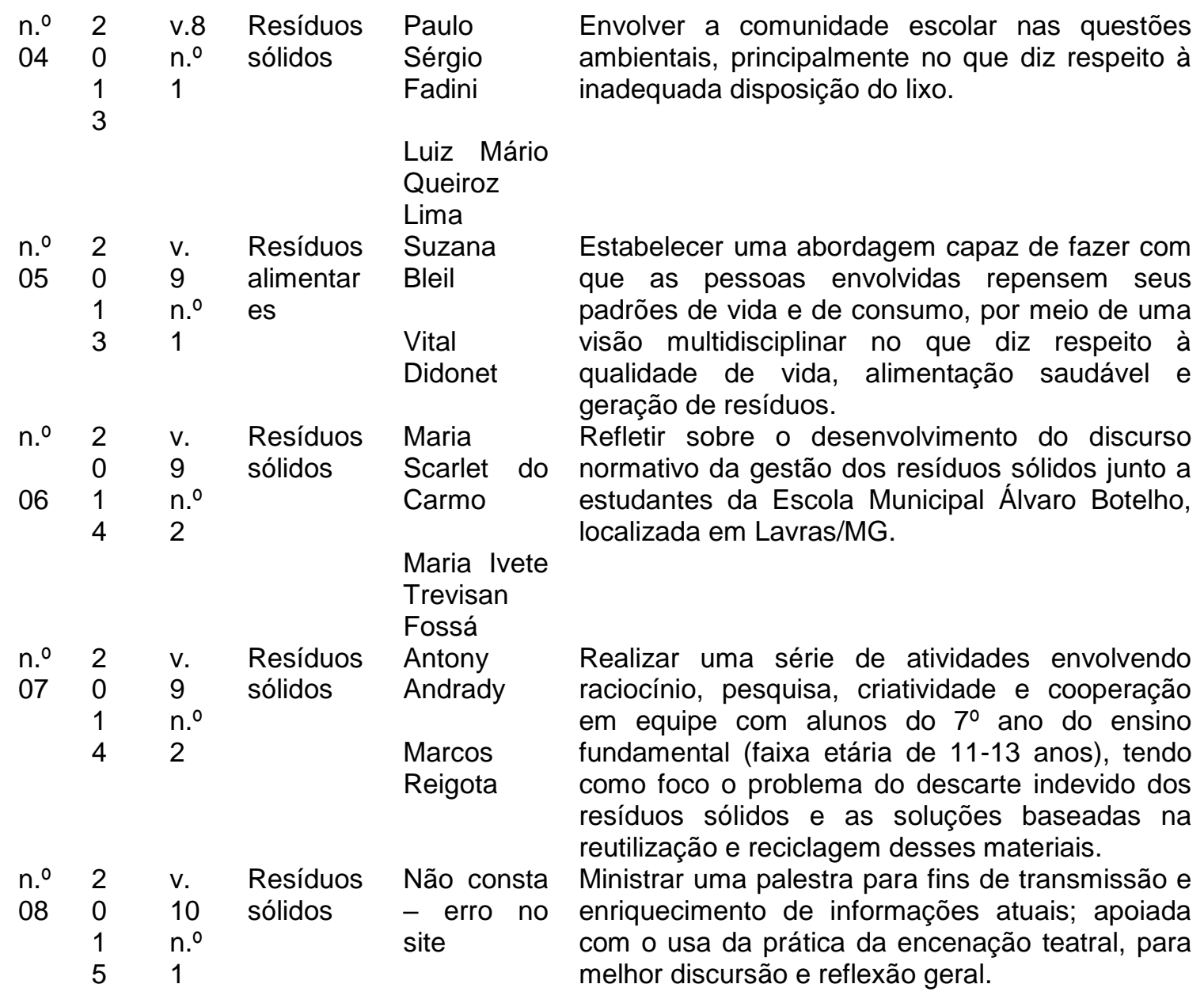

Continua..

Revbea, São Paulo, V. 13, № 3: 316-333, 2018. 
...continuação.

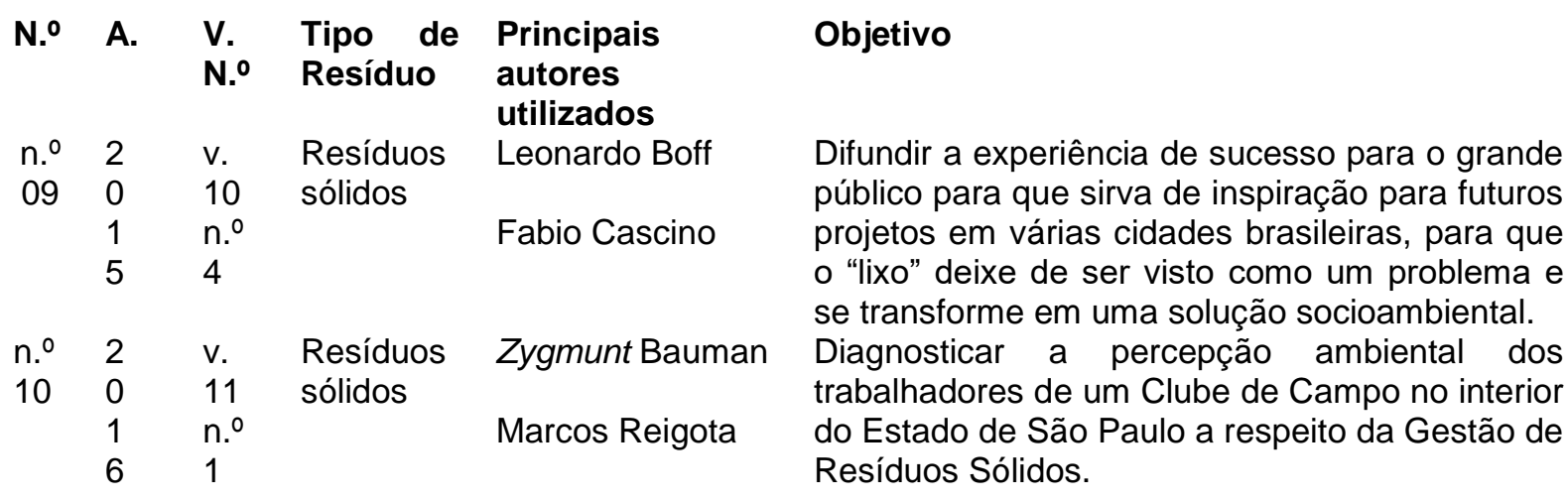

$\begin{array}{cccclc}\text { n. ㅇ } & 2 & \text { v. } & \text { Resíduos } & \text { Nádia } & \text { Bolzan } \\ 11 & 0 & 11 & \text { sólidos } & \text { Soares } & \\ & 1 & \text { n. }{ }^{-} & & & \\ & 6 & 1 & & \text { João } & \text { José } \\ & & & & \begin{array}{l}\text { Saraiva } \\ \text { da Fonseca }\end{array}\end{array}$

Continuação Analisar as percepções de alunos da educação de jovens e adultos sobre o gerenciamento de resíduos sólidos.

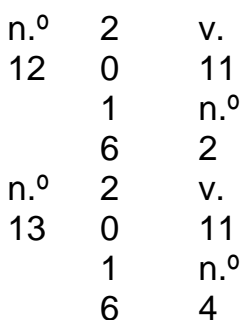

$\begin{array}{lll}\text { ก. } & 2 & \text { v. } \\ 14 & 0 & 11 \\ & 1 & \text { n.․ } \\ & 6 & 4\end{array}$

Resíduos sólidos ก.음

2

Resíduos sólidos n. 4
Michel Thiollent

Myriam Krasilchik

Márcio Magera

Paula

Orchiucci Miura
Resíduos Berenice Gehlen sólidos ก.

\section{Adams}

Alexandre Luiz Alvez

$\begin{array}{llllll}\text { n.․․ } & 2 & \text { v. } & \text { Resíduos } & \text { Lucie Sauvé } \\ 15 & 0 & 11 & \text { sólidos } & & \\ & 1 & \text { n.․ } & \text { urbanos } & \begin{array}{l}\text { Pedro } \\ \text { Jacobi }\end{array} & \text { Roberto } \\ & 6 & 4 & & & \end{array}$

Realizar a gestão de resíduos da ETEC Augusto Tortolero Araújo por alunos do 10 ano do Ensino Médio

Analisar os Planos de Gerenciamento de Resíduos Sólidos de cinco (5) municípios situados na Região Centro-Oeste do Estado do Rio Grande do Sul, atendendo a Lei 12. 305/10 que incentiva a coleta seletiva, a integração dos catadores de materiais recicláveis em cooperativas e também a inserção desses munícipes na economia local.

Apresentar um Programa de EA para o município de São José da Lapa (MG) que tem como objetivo a proposição de atividades teórico-práticas que promovam a ação integrada dos 7setores público, privado e da sociedade civil, visando a melhoria do gerenciamento de resíduos sólidos urbanos do município Sensibilizar os participantes do Programa Escola da Família na Instituição de Ensino Antônio Militão de Lima, localizado no município de São Carlos - SP

\section{$\begin{array}{lll}\mathrm{n} . \stackrel{0}{ } \quad 2 & \mathrm{v} .1\end{array}$ \\ $\begin{array}{lll}16 & 0 & 1\end{array}$ \\ $\begin{array}{ll}1 & \text { ก. } .^{-} \\ 6 & 5\end{array}$ \\ Resíduos Genebraldo Dias sólidos escolares \\ Lucie Sauvé}

Relatar um projeto de reciclagem em uma escola de Novo Hamburgo - RS

Notas: N.․․: número; V.: volume; A.: ano.

Fonte: RevBEA, 2016. Elaboração: KREUZ, 2016. 
O Quadro 4, apresenta pesquisas da RevBEAque trabalharam com 0 tema de EA na escola ou colégio, abrangendo diferentes abordagens e objetivos. $\mathrm{O}$ ano de que mais apareceu nas pesquisas, foi o $9^{\circ}$ ano do Ensino Fundamental II, aparecendo especificamente em três (3) pesquisas. No geral, o Ensino Fundamental demonstrou ser o maior foco de abordagem, sendo que o Ensino Médio apareceu apenas uma vez com especificidade na pesquisa. Dentre os autores mais utilizados pelos pesquisadores, estão Paulo Freire e Mauro Guimarães.

Quadro 4: Pesquisas com o tema de Escola/Colégio.

\begin{tabular}{|c|c|c|c|c|c|}
\hline N.ㅇ & A. & $\begin{array}{l}\text { V. } \\
\text { N.o }\end{array}$ & $\begin{array}{l}\text { Grau de } \\
\text { Ensino }\end{array}$ & $\begin{array}{l}\text { Principais } \\
\text { autores } \\
\text { utilizados }\end{array}$ & Objetivo \\
\hline $\begin{array}{l}\text { n. } . \\
01\end{array}$ & $\begin{array}{l}2 \\
0 \\
1 \\
0\end{array}$ & v. 5 & $\begin{array}{l}4^{\circ} \text { e } 5^{\circ} \\
\text { série do } \\
\text { Ensino } \\
\text { Fundame } \\
\text { ntal }\end{array}$ & $\begin{array}{l}\text { Genebaldo } \\
\text { Dias } \\
\text { Mauro } \\
\text { Guimarães }\end{array}$ & $\begin{array}{l}\text { Verificar como a EA está inserida no planejamento de } \\
\text { ensino, realizando um estudo do nível de } \\
\text { conscientização ambiental de alunos e professores da } \\
\text { rede municipal de ensino de um pequeno município do } \\
\text { estado do (RS). }\end{array}$ \\
\hline $\begin{array}{l}\text { n. } . \\
02\end{array}$ & $\begin{array}{l}2 \\
0 \\
1 \\
1\end{array}$ & $\begin{array}{l}\text { v. } \\
6\end{array}$ & $\begin{array}{l}9^{\circ} \text { ano do } \\
\text { Ensino } \\
\text { Fundame } \\
\text { ntal }\end{array}$ & $\begin{array}{l}\text { Paulo } \\
\text { Freire } \\
\text { Sandra } \\
\text { Maria } \\
\text { Souza de } \\
\text { Oliveira }\end{array}$ & $\begin{array}{l}\text { Identificar e analisar as representações sociais de } \\
\text { Meio Ambiente dos professores e alunos das escolas } \\
\text { públicas da área urbana e rural em Teófilo Otoni-MG, } \\
\text { e sua relação com os projetos de EA desenvolvidos } \\
\text { nessas escolas. }\end{array}$ \\
\hline $\begin{array}{l}\text { n. } . \\
03\end{array}$ & $\begin{array}{l}2 \\
0 \\
1 \\
2\end{array}$ & $\begin{array}{l}\text { v. } \\
7 \\
\text { n. } . \\
1\end{array}$ & $\begin{array}{l}\text { Toda a } \\
\text { comunide } \\
\text { escolar }\end{array}$ & $\begin{array}{l}\text { Sabetai } \\
\text { Calderoni } \\
\text { Edgar } \\
\text { Morin }\end{array}$ & $\begin{array}{l}\text { Apresentar experiências relativas ao desenvolvimento } \\
\text { de um projeto de EA na Escola Coronel Murilo Serpa, } \\
\text { localizada no bairro Cruzeiro, em Itapipoca - CE. }\end{array}$ \\
\hline $\begin{array}{l}n .0 \\
04\end{array}$ & $\begin{array}{l}2 \\
0 \\
1 \\
2\end{array}$ & $\begin{array}{l}\text { v. } \\
7 \\
\text { n. } \\
1\end{array}$ & $\begin{array}{l}\text { Ensino } \\
\text { Fundame } \\
\text { ntal I e II } \\
\text { e o EJA }\end{array}$ & $\begin{array}{l}\text { Marcos } \\
\text { Reigota } \\
\text { Michele } \\
\text { Sato }\end{array}$ & $\begin{array}{l}\text { Conhecer a percepção dos professores sobre meio } \\
\text { ambiente. }\end{array}$ \\
\hline $\begin{array}{l}\text { n. } . \\
05\end{array}$ & $\begin{array}{l}2 \\
0 \\
1 \\
3\end{array}$ & $\begin{array}{l}\text { v. } 8 \\
\text { ก. } .0 \\
1\end{array}$ & $\begin{array}{l}\text { Todos os } \\
\text { anos do } \\
\text { Ensino } \\
\text { Fundame } \\
\text { ntal II }\end{array}$ & $\begin{array}{l}\text { Heloísa } \\
\text { Helena } \\
\text { Martins } \\
\text { Gloria } \\
\text { Serrano }\end{array}$ & $\begin{array}{l}\text { Avaliar a formação dos educadores do Colégio Théo } \\
\text { Brandão para a prática da EA (EA). }\end{array}$ \\
\hline $\begin{array}{l}\text { n. } . \\
06\end{array}$ & $\begin{array}{l}2 \\
0 \\
1 \\
3\end{array}$ & $\begin{array}{l}\text { v. } \\
8 \\
\text { n. } . \\
2\end{array}$ & $\begin{array}{l}5^{\circ} \text { ano do } \\
\text { Ensino } \\
\text { Fundame } \\
\text { ntal }\end{array}$ & $\begin{array}{l}\text { Mauro } \\
\text { Guimarães }\end{array}$ & $\begin{array}{l}\text { Enfocar um estudo de caso participante realizado em } \\
\text { uma escola da rede pública em São Luís (MA). }\end{array}$ \\
\hline
\end{tabular}

Continua... 
...continuação.

\begin{tabular}{|c|c|c|c|c|c|}
\hline N.․ & A. & $\begin{array}{l}\text { V. } \\
\text { N.․․ }\end{array}$ & $\begin{array}{l}\text { Grau } \\
\text { Ensino }\end{array}$ & $\begin{array}{l}\text { Principais } \\
\text { autores } \\
\text { utilizados }\end{array}$ & Objetivo \\
\hline 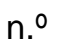 & 2 & v. & 9o ano do & Paulo & Refletir em relação aos óleos alimentares, que \\
\hline 07 & $\begin{array}{l}0 \\
0 \\
9\end{array}$ & $\begin{array}{l}9 \mathrm{n} . \\
1\end{array}$ & $\begin{array}{l}\text { Ensino } \\
\text { Fundamental }\end{array}$ & $\begin{array}{l}\text { Freire } \\
\text { Pedro } \\
\text { Roberto } \\
\text { Jacobi }\end{array}$ & $\begin{array}{l}\text { são resíduos gerados diariamente por lares e } \\
\text { indústrias alimentícias e descartados } \\
\text { erroneamente em diferentes locais e seus } \\
\text { efeitos no meio ambiente, utilizando um grupo } \\
\text { focal para detecção dessa problemática em } \\
\text { sala de aula. }\end{array}$ \\
\hline ก. $\stackrel{\circ}{-}$ & 2 & v. & Todas as & Paulo & Abordar temas ambientais relacionados à \\
\hline 08 & $\begin{array}{l}0 \\
0\end{array}$ & $\begin{array}{l}9 \\
\text { n. }\end{array}$ & $\begin{array}{l}\text { séries do } \\
\text { Ensino }\end{array}$ & Freire & $\begin{array}{l}\text { água, alimentação, resíduos sólidos (lixo) e } \\
\text { biodiversidade na escola municipal Neuza dos }\end{array}$ \\
\hline & 9 & 1 & Fundamental & $\begin{array}{l}\text { Mauro } \\
\text { Guimarães }\end{array}$ & $\begin{array}{l}\text { Santos Ribeiro localizada na associação } \\
\text { Agro-Comunitária dos Moradores do Ramal } \\
\text { do Pau Rosa/AM no Assentamento Tarumã- } \\
\text { Mirim, em Manaus. }\end{array}$ \\
\hline n. - & 2 & v. & Ensino & Rubens & Buscar definições do que é meio ambiente e \\
\hline 09 & $\begin{array}{l}0 \\
0 \\
9\end{array}$ & $\begin{array}{l}9 \\
\text { ก. } \\
2\end{array}$ & $\begin{array}{l}\text { Fundamental } \\
\text { II }\end{array}$ & $\begin{array}{l}\text { Alves } \\
\text { Enrique } \\
\text { Leff }\end{array}$ & $\begin{array}{l}\text { seu valor, desmistificar conceitos equivocados } \\
\text { sobre o tema meio ambiente e analisar como o } \\
\text { tema é trabalhado na escola. }\end{array}$ \\
\hline $\begin{array}{l}\text { n. } .9 \\
10\end{array}$ & $\begin{array}{l}2 \\
0\end{array}$ & $\begin{array}{l}\text { v. } 9 \\
\text { ก. } .9\end{array}$ & $\begin{array}{l}\text { 60 ano do } \\
\text { Ensino }\end{array}$ & $\begin{array}{l}\text { Carlos } \\
\text { Frederico }\end{array}$ & $\begin{array}{l}\text { Compreender como a EA é abordada no } \\
\text { ensino; perceber se são tecidas relações entre }\end{array}$ \\
\hline & $\begin{array}{l}0 \\
9\end{array}$ & 2 & Fundamental & $\begin{array}{l}\text { Loureiro } \\
\text { Marcos } \\
\text { Reigota }\end{array}$ & $\begin{array}{l}\text { a EA, a realidade dos educandos e os } \\
\text { conteúdos escolares; e entender como a EA } \\
\text { pode servir como aspecto desencadeador } \\
\text { para uma tomada de consciência. }\end{array}$ \\
\hline $\mathrm{n} . \stackrel{\circ}{-}$ & 2 & v. 9 & Todas as & Gisele & Expor algumas reflexões acerca das \\
\hline 11 & $\begin{array}{l}0 \\
0 \\
9\end{array}$ & $\begin{array}{l}n \cdot .-0 \\
2\end{array}$ & $\begin{array}{l}\text { séries do } \\
\text { Ensino } \\
\text { Médio }\end{array}$ & $\begin{array}{l}\text { Silva Barbo } \\
\text { sa }\end{array}$ & $\begin{array}{l}\text { definições, da importância e da aplicabilidade } \\
\text { da EA na Educação Básica, a partir de } \\
\text { práticas desenvolvidas no Colégio Pedro II - }\end{array}$ \\
\hline & & & & $\begin{array}{l}\text { Pedro } \\
\text { Jacobi }\end{array}$ & $\begin{array}{l}\text { Campus São Cristóvão III, localizado na } \\
\text { cidade do Rio de Janeiro. }\end{array}$ \\
\hline n. $\stackrel{\circ}{-}$ & 2 & v. & Todas as & Aloma & Analisar como os professores das Escolas \\
\hline 12 & $\begin{array}{l}0 \\
1 \\
5\end{array}$ & $\begin{array}{l}10 \\
\text { n.o } \\
1\end{array}$ & $\begin{array}{l}\text { séries do } \\
\text { Ensino } \\
\text { Médio }\end{array}$ & $\begin{array}{l}\text { Carvalho } \\
\text { Henrique } \\
\text { Leff }\end{array}$ & $\begin{array}{l}\text { Públicas Estaduais de Floresta - PE vem } \\
\text { trabalhando as questões ambientais. }\end{array}$ \\
\hline n. $\stackrel{0}{\circ}$ & 2 & v. & $8^{\circ}$ e $9^{\circ}$ & Isabel & Diagnosticar a situação da EA na Escola \\
\hline 13 & 0 & 10 & Ensino & Cristina & Municipal Severino Bezerra, no município de \\
\hline & $\begin{array}{l}1 \\
5\end{array}$ & $\begin{array}{l}\text { n. } . \\
2\end{array}$ & Fundamental & $\begin{array}{l}\text { Carvalho } \\
\text { Tiago } \\
\text { Fenster- } \\
\text { seifer }\end{array}$ & Pau dos Ferros-RN \\
\hline
\end{tabular}

Notas: N.․․: número; V.: volume; A.: ano.

Fonte: RevBEA, 2017. Elaboração: KREUZ, 2017. 
O Quadro 5 apresenta as oito (8) pesquisas da RevBEA trabalharam com o tema de ecologia, abrangendo diferentes abordagens e objetivos. A autora mais utilizada pelos pesquisadores foi Isabel Cristina Moura Carvalho.

Quadro 5: Pesquisas com o tema de ecologia.

\begin{tabular}{|c|c|c|c|c|}
\hline N.․․ & A. & $\begin{array}{l}\text { V. } \\
\text { N.o }\end{array}$ & $\begin{array}{l}\text { Principais } \\
\text { autores } \\
\text { utilizados }\end{array}$ & Objetivo \\
\hline 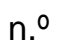 & 2 & v. & Durval Muniz & Explorar problematizações \\
\hline \multirow[t]{2}{*}{01} & $\begin{array}{l}0 \\
1 \\
2\end{array}$ & $\begin{array}{l}7 \\
\text { ก. }-9 \\
2\end{array}$ & $\begin{array}{l}\text { Albuquerque } \\
\text { Júnior }\end{array}$ & nordestinidade e EA. \\
\hline & & & larcos Reigota & \\
\hline 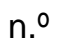 & 2 & v. 9 & abel Cristina de & Analisar o conceito de sujeito ecológico e suas contribuições \\
\hline 02 & $\begin{array}{l}0 \\
1 \\
4\end{array}$ & $\begin{array}{l}\text { n. } . \stackrel{-}{2} \\
2\end{array}$ & $\begin{array}{l}\text { Moura Carvalho } \\
\text { Ignacy Sachs }\end{array}$ & $\begin{array}{l}\text { ao debate teórico-conceitual no amplo quadro da EA crítico- } \\
\text { transformadora, hoje em disputa no Brasil e na América } \\
\text { Latina em geral. }\end{array}$ \\
\hline n. ${ }^{\circ}$ & 2 & v. & Sabetai & Analisar a relevância da EA na efetivação do sistema de \\
\hline \multirow[t]{2}{*}{03} & $\begin{array}{l}0 \\
1\end{array}$ & $\begin{array}{l}9 \\
\text { n. } .0\end{array}$ & Calderoni & $\begin{array}{l}\text { coleta de lixo, bem como, as práticas ecológicas adotadas } \\
\text { pela instituição. }\end{array}$ \\
\hline & 4 & 2 & Enrique Leff & \\
\hline n.. & 2 & v. & abel Cristina de & Analisar os projetos de EA realizados em uma escola da \\
\hline \multirow[t]{2}{*}{04} & 0 & 9 & Moura Carvalho & Rede Municipal de Ensino de Curitiba durante os anos de \\
\hline & $\begin{array}{l}1 \\
4\end{array}$ & $\begin{array}{l}\text { n. } .9 \\
2\end{array}$ & & \\
\hline \multirow{2}{*}{$\begin{array}{l}n .0 \\
05\end{array}$} & 2 & v. 9 & Enrique Leff & Conhecer a percepção que os estudantes do Instituto Feral \\
\hline & $\begin{array}{l}0 \\
1 \\
4\end{array}$ & $\begin{array}{l}\text { n. } .9 \\
2\end{array}$ & Lucie Sauvé & $\begin{array}{l}\text { do Triângulo Mineiro - Campus Uberlândia têm acerca do } \\
\text { projeto de coleta seletiva cujo objetivo é implantar um } \\
\text { Programa de Gerenciamento de Resíduos Sólidos em seu } \\
\text { campus, contemplando a redução de geração na fonte, a } \\
\text { separação dos resíduos recicláveis descartados e a } \\
\text { destinação final adequada. }\end{array}$ \\
\hline \multirow{4}{*}{ n. $=$} & 2 & v. & Isabel Cristina de & Analisar as concepções sobre Natureza, Meio Ambiente e EA \\
\hline & 0 & 11 & Moura Carvalho & trazida pelos alunos de $6^{\circ}$ e $7^{\circ}$ anos do ensino fundamental \\
\hline & 1 & n.. & & II, e posteriormente ressignificá-las através de uma trilha \\
\hline & 6 & 1 & $\begin{array}{l}\text { Genebaldo Freire } \\
\text { Dias }\end{array}$ & ecológica. \\
\hline \multirow{2}{*}{$\begin{array}{l}n .0 \\
07\end{array}$} & 201 & v. & Rubens Alves & Discutir a importância de atividades práticas e lúdicas na EA \\
\hline & & $\begin{array}{l}11 \\
\text { ก. } . \\
1\end{array}$ & Lev Vygotsky & $\begin{array}{l}\text { de crianças de } 4-5 \text { anos e seus reflexos na relação } \\
\text { professor-aluno e na motivação docente. }\end{array}$ \\
\hline \multirow{2}{*}{$\begin{array}{l}n+- \\
08\end{array}$} & 201 & & Antonio & Analisar dois (2) projetos responsáveis por algumas práticas \\
\hline & 6 & $\begin{array}{l}11 \\
\text { n.. } \\
5\end{array}$ & $\begin{array}{l}\text { Carlos Diegues } \\
\text { Vilmar } \\
\text { Alves Pereira }\end{array}$ & $\begin{array}{l}\text { incentivadas pelo Estado em um espaço pesqueiro artesanal, } \\
\text { junto a Laguna dos Patos no estado do Rio Grande do Sul, } \\
\text { Brasil, na década de } 90 \text {. }\end{array}$ \\
\hline
\end{tabular}

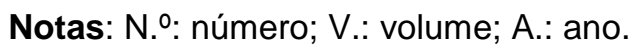


O Quadro 6 apresenta as sete (7) pesquisas trabalharam com o tema de sustentabilidade, abrangendo diferentes abordagens. Os autores mais citados foram Paulo Freire e Paulo Roberto Jacobi.

Quadro 6: Pesquisas com o tema de sustentabilidade.

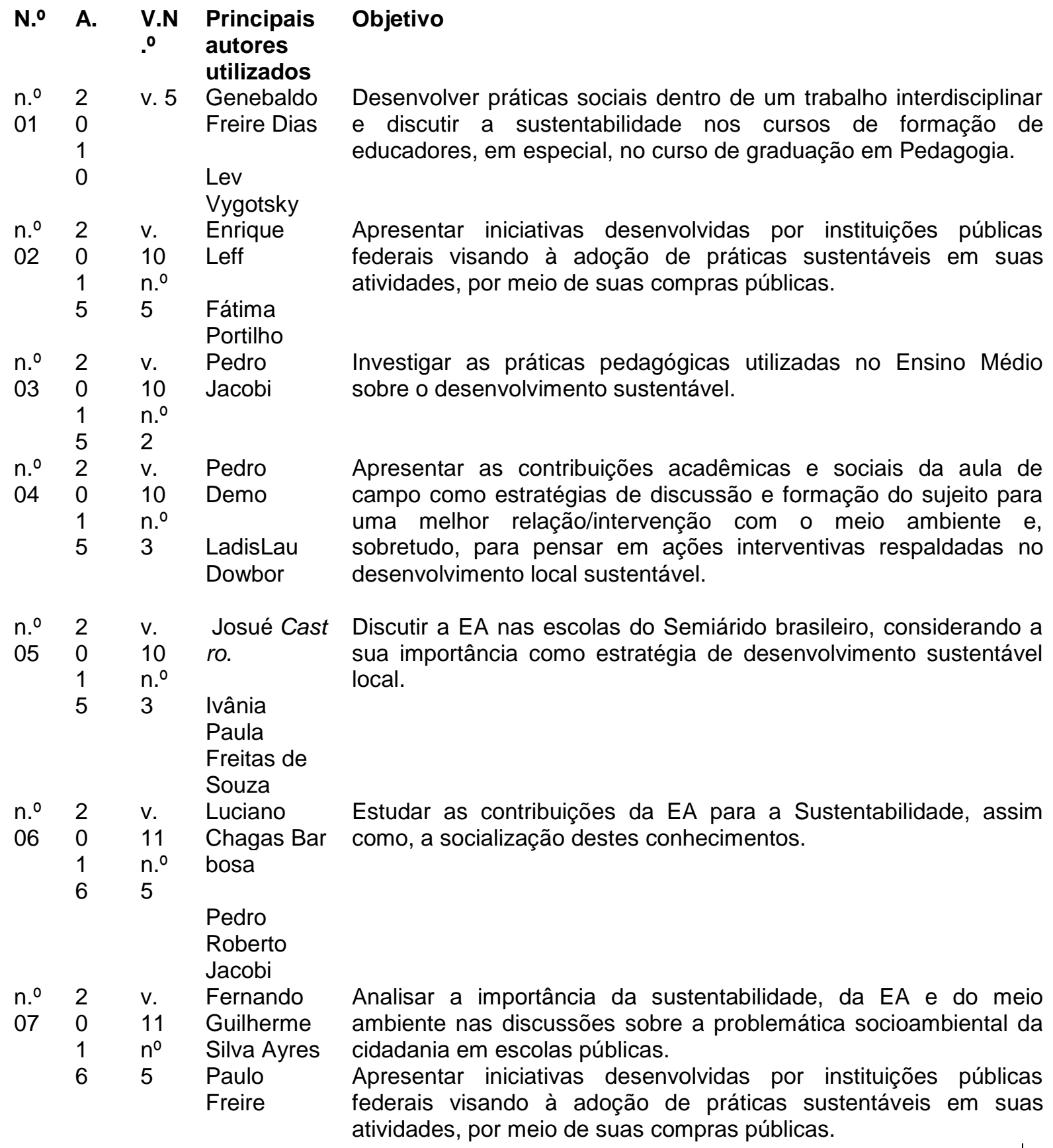

Notas: N.․: número; V.: volume; A.: ano.

Fonte: RevBEA, 2017. Elaboração: KREUZ, 2017. 
O Quadro 7 apresenta as sete (7) pesquisas trabalharam com o tema de Ensino Fundamental, abrangendo diferentes abordagens. Os anos de formação que mais apareceram nas pesquisas, foi o 6ㅇ e 9을 ano do Ensino Fundamental II, aparecendo especificamente em três (3) pesquisas cada. $\mathrm{O}$ autor mais utilizado pelos pesquisadores foi Pedro Jacobi.

Quadro 7: Pesquisas com o tema de Ensino Fundamental.

\begin{tabular}{|c|c|c|c|c|}
\hline 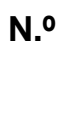 & A. & $\begin{array}{l}\text { V. } \\
\text { N.․ }\end{array}$ & $\begin{array}{l}\text { Ano de } \\
\text { formação }\end{array}$ & $\begin{array}{l}\text { Principa } \\
\text { autores } \\
\text { utilizado }\end{array}$ \\
\hline 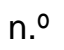 & 2 & v. & Todos os & Pedro \\
\hline \multirow[t]{3}{*}{01} & 0 & 5 & anos do & Roberto \\
\hline & 10 & n. $\stackrel{\circ}{-}$ & Ensino & Jacobi \\
\hline & & 10 & Fundamental & \\
\hline $\mathrm{n} . \stackrel{\circ}{-}$ & 2 & v. 8 & $2^{\circ} 4^{\circ} 6^{\circ}$ e $9^{\circ}$ & Marcos \\
\hline \multirow[t]{3}{*}{02} & 0 & n.. & ano & Reigota \\
\hline & 1 & 1 & & Enrique \\
\hline & 3 & & & Leff \\
\hline
\end{tabular}

$\begin{array}{lllll}\text { n. } . & 2 & \text { v. } & \text { Todo o Ensino } & \text { Marcos } \\ 03 & 0 & 9 & \text { Fundamental } & \text { Dantas } \\ & 1 & \text { n. } . & & \text { Santos } \\ & 4 & 1 & & \end{array}$

Carlos

Rodrigues

Brandão

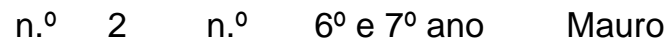
$040 \quad 1$ v. do Ensino Reigota
$1 \quad 1 \quad$ Fundamental

6

v.1 9o série do

$0501 \mathrm{n}$. Ensino Freire

11 Fundamental Pedro

6 Roberto

Jacobi

$\begin{array}{lllll}\text { n.ำ } & 2 & \text { v.1 } & \text { Todos os } & \text { Werther } \\ 06 & 0 & 1 & \text { anos do } & \text { Holzer } \\ & 1 & \text { n.ำ } & \text { Ensino } & \text { Philippe } \\ & 6 & 4 & \text { Fundamental } & \text { Layrargues }\end{array}$
n. 2 v.1 6ำ e 9a ano do Chênia
$\begin{array}{lllll}07 & 0 & 1 & \text { Ensino } & \text { Rocha }\end{array}$
$1 \quad$ ก..$\quad$ Fundamental Figueiredo
65 José Gol-
demberg

\section{Objetivo}

Verificar o que os professores entendem por EA, como trabalham a temática ambiental.

Verificar como a EA (EA) se concretiza na escola, mediante a análise dos discursos de professores e alunos de uma escola municipal de Palmas (TO), a partir das propostas de políticas públicas educacionais, utilizando o enfoque da Análise do Discurso (AD) e da EA.

Apresentar dados sobre a população de aves e árvores frutíferas existentes na cidade de Ilha Solteira - SP

Investigar as concepções sobre meio ambiente de estudantes do Ensino Fundamental e a partir dessa análise apresentar a importância da preservação do meio ambiente em um ambiente escolar.

Verificar o entendimento dos conceitos básicos que permeiam a EA e perceber o entendimento geral dos alunos da série final do ensino básico, do município de Cruz das Almas-Bahia.

Identificar como alunos de duas (2) escolas públicas situadas no município de Jaboticabal-SP percebem a interação entre o ambiente rural e urbano e quais ações é feitas frente aos problemas ambientais.

Apresentar o projeto que teve por intuito instruir alunos sobre a importância e a presença da energia no cotidiano, suas formas de geração e impactos ambientais advindos de sua utilização.

Notas: N...: número; V.: volume; A.: ano. 
Foram cinco (5) as pesquisas que trabalharam com o tema de lixo, abrangendo diferentes abordagens e objetivos. Nenhum autor apareceu em mais de um artigo ou relato de experiência (Quadro 8).

Quadro 8: Pesquisas com o tema de lixo.

\begin{tabular}{|c|c|c|c|}
\hline N.. & A. & $\begin{array}{l}\text { V.은 } \\
\text { N.. }\end{array}$ & $\begin{array}{l}\text { Principais } \\
\text { utilizados }\end{array}$ \\
\hline $\begin{array}{l}\text { n. } . \\
01\end{array}$ & $\begin{array}{l}2 \\
0 \\
1 \\
0\end{array}$ & v. 5 & $\begin{array}{l}\text { José Murilo Carvalho } \\
\text { Antônio Edimir Frota } \\
\text { Fernandes }\end{array}$ \\
\hline $\begin{array}{l}\mathrm{n} . \stackrel{\circ}{ } \\
02\end{array}$ & $\begin{array}{l}2 \\
0 \\
1 \\
0\end{array}$ & v. 5 & $\begin{array}{l}\text { Sandra Branco } \\
\text { Eduardo Beltrão de Lucena } \\
\text { Córdula }\end{array}$ \\
\hline $\begin{array}{l}\text { n. } . \\
03\end{array}$ & $\begin{array}{l}2 \\
0 \\
1 \\
4\end{array}$ & $\begin{array}{l}\text { v. } 9 \\
\text { n. } 92\end{array}$ & $\begin{array}{l}\text { Vera Lúcia de Jesus } \\
\text { Débora Cinosi Silva }\end{array}$ \\
\hline $\begin{array}{l}\text { n. } . \\
04\end{array}$ & $\begin{array}{l}2 \\
0 \\
1 \\
5\end{array}$ & $\begin{array}{l}\text { v. } 10 \\
\text { n. } .5\end{array}$ & $\begin{array}{l}\text { Isabel Cristina de } \\
\text { Moura Carvalho } \\
\text { Carlos Loureiro }\end{array}$ \\
\hline $\begin{array}{l}\mathrm{n} . \stackrel{\circ}{0} \\
05\end{array}$ & $\begin{array}{l}2 \\
0 \\
1 \\
6\end{array}$ & $\begin{array}{l}\text { v. } 11 \\
\text { n. } .2\end{array}$ & $\begin{array}{l}\text { Rosimeire de Souza } \\
\text { Antônio Carlos Gil }\end{array}$ \\
\hline
\end{tabular}

Analisar a questão da preservação do meio ambiente, a necessidade de EA e o desenvolvimento sustentável.

Sensibilizar alunos do Ensino Fundamental em relação à má disposição do lixo.

Investigar como a EA e a questão do lixo como problemática ambiental pode contribuir para formação voltada à cidadania.

Analisar quais as concepções de EA dos associados da ACREVI no ano de 2009.

Analisar um Programa Castellense de Coleta Seletiva de Lixo, desenvolvido desde o ano de 2007 no município de Presidente Castello Branco localizado no oeste de Santa Catarina.

Notas: N..:- número; V.: volume; A.: ano.

Fonte: RevBEA, 2017. Elaboração: KREUZ, 2017.

O Quadro 9 apresenta as cinco (5) pesquisas da RevBEA trabalharam com o tema de percepção ambiental, abrangendo diferentes abordagens e objetivos. $\mathrm{O}$ autor mais utilizado pelos pesquisadores foi Henrique Leff. 
Quadro 9: Pesquisas com o tema de percepção ambiental.

\begin{tabular}{|c|c|c|c|}
\hline N.의 & A. & 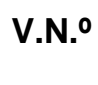 & $\begin{array}{l}\text { Principais autores } \\
\text { utilizados }\end{array}$ \\
\hline $\begin{array}{l}\text { n. } . \stackrel{0}{0} \\
01\end{array}$ & $\begin{array}{l}2 \\
0 \\
1 \\
0\end{array}$ & v. 5 & $\begin{array}{l}\text { Sandra Faggionato } \\
\text { Jackson Muller }\end{array}$ \\
\hline $\begin{array}{l}\text { n. } .9 \\
02\end{array}$ & $\begin{array}{l}2 \\
0 \\
1 \\
1\end{array}$ & v. 6 & $\begin{array}{l}\text { Beatriz Regina Dorfman } \\
\text { Yi-Fu Tuan }\end{array}$ \\
\hline $\begin{array}{l}\text { n. } . \stackrel{-}{0} \\
03\end{array}$ & $\begin{array}{l}2 \\
0 \\
1 \\
2\end{array}$ & $\begin{array}{l}\text { v. } 7 \\
\text { n. }-1\end{array}$ & $\begin{array}{l}\text { Marcos Reigota } \\
\text { Michele Sato }\end{array}$ \\
\hline $\begin{array}{l}\text { n. } .9 \\
04\end{array}$ & $\begin{array}{l}2 \\
0 \\
1 \\
3\end{array}$ & $\begin{array}{l}\text { v. } 8 \\
\text { n. } .91\end{array}$ & $\begin{array}{l}\text { Mauro Guimarães } \\
\text { Enrique Leff }\end{array}$ \\
\hline $\begin{array}{l}\text { n. } .9 \\
05\end{array}$ & $\begin{array}{l}2 \\
0 \\
1 \\
4\end{array}$ & $\begin{array}{l}\text { v. } 9 \\
\text { n. } .2\end{array}$ & $\begin{array}{l}\text { Enrique Leff } \\
\text { Jun } \\
\text { Okamoto }\end{array}$ \\
\hline
\end{tabular}

Analisar a percepção ambiental de universitários e sensibilizar quanto aos impactos ambientais da disposição de resíduos sólidos urbanos (RSU) em um antigo local de disposição de resíduos de Passo Fundo, RS.

Identificar a percepção de identidade da flora brasileira, de universitários, já que reconhecer a biodiversidade nativa é um valor cultural e potencial para processos de conscientização/ conservação da natureza e também para as proposições de desenvolvimento local.

Conhecer a percepção dos professores sobre meio ambiente.

Avaliar o nível de percepção dos alunos de ensino médio (10 e 20 ano) sobre a EA.

Buscar definições do que é meio ambiente e seu valor, desmistificar conceitos equivocados sobre o tema meio ambiente e analisar como o tema é trabalhado na escola.

Notas: N...: número; V.: volume; A.: ano

Fonte: RevBEA, 2017. Elaboração: KREUZ, 2017.

As sete (7) temáticas apresentadas representam $24 \%$ das pesquisas da Revista, demonstrando serem problemáticas que instigam e abrangem muitos pesquisadores. Com isso, é importante analisar como essas questões se desenvolvem e como são trabalhadas pelos autores da revista.

\section{Considerações}

A busca da totalidade do que já foi analisado, encontrado ou "descoberto" em determinado campo do conhecimento é um desejo dos pesquisadores. Contudo, para que a finalidade do estado da arte seja concretizada, é necessário que haja articulação e integração das diferentes produções analisadas.

Com o desafio de mapear as produções, entre artigos e relatos de experiência que discutem diferentes campos teóricos e metodológicos, foi possível compreender alguns aspectos comuns e distintos da EA. Justamente com a necessidade de articulação e integração desses aspectos, que as pesquisas foram subdivididas em temas. 
Percebe-se que o que caracteriza as pesquisas em EA, são os diversos projetos que visam à sensibilização de sujeitos, em relação aos problemas ambientais. Independentemente de esse ser, ou não, o foco ou temática principal da pesquisa, esses, normalmente são os resultados almejados e alcançados. Se a pesquisa abrange resíduos sólidos, o objetivo normalmente é sensibilizar sujeitos em relação às problemáticas causadas pela má disposição dos mesmos. Se a pesquisa é sobre recursos hídricos, é o de sensibilizar determinados sujeitos em relação a importância e escassez do recurso. Isto normalmente ocorre sucessivamente com as demais temáticas.

Obviamente que o papel da EA é o de preparar os sujeitos para que sensibilizados, transformem seus valores em relação ao meio ambiente. Porém, ao mesmo tempo em que é um aspecto positivo, verifica-se que cada vez mais projetos de EA estão sendo desenvolvidos e concluídos com esse objetivo, e aparentemente com resultados satisfatórios. Contudo, é desanimador perceber que não há evolução nesses aspectos e que esse fator aparenta ser contínuo ao longo dos anos. Sendo que além de valores, atitudes são essenciais para solucionar essas problemáticas.

A RevBEA, desde sua primeira edição demonstra, por meio das produções, grande importância para o contexto nacional. Abrange todas as áreas do conhecimento, já que não é uma específica que atua nesse campo. As diversas vivências relatadas, experiências descritas, ensaios e/ou reflexões teóricas apresentadas nas publicações, demonstram a heterogeneidade na natureza das pesquisas e a ecleticidade teórica e conceitual das publicações.

A importância da EA nas diversas áreas, e as problemáticas referentes a esse tema, são tão significativas, que necessitam cada vez mais de pesquisas. As 253 publicações com disponibilidade on-line, em sete (7) anos, representam essa busca por reflexões e soluções de problemas no âmbito da EA. Além disso, a atenção dada a essas questões cresceu ano após ano, o que é demonstrado pelo aumento do número de publicações da Revista. Outro dado que aponta a relevância da EA, é o número de autores envolvidos nas publicações, totalizando 689. A maioria deles, trabalhando em conjunto, desenvolvem pesquisas, tanto bibliográficas, como estudos de casos, documental, pesquisa-ação, entre outros.

\section{Referências}

FERREIRA, N.S.A. As Pesquisas Denominadas "Estado da Arte". Educação e Sociedade, 2002, vol. 23, n.79, pp.257-272.

LOUREIRO, C.F.B. Problematizando Conceitos: Contribuição à Práxis da Educação Ambiental. In: LOUREIRO, C.F.B.; LEROY, J.P (Orgs.). Pensamento Complexo, Dialética e Educação Ambiental. São Paulo: Cortez, 2006 c.

ZANELLA, J.L. Matrizes Modernas do Conceito de Natureza: As Filosofias

Baconiana e Cartesiana. In. FRANCISCHETT, M.N.; TOFFOLO, G. Educação Ambiental Na Perspectiva da Pesquisa Qualitativa. Cascavel: EDUNIOESTE, 2012. pp.00-00. Coloque a primeira e a última página. 